\title{
CULTURAL HERITAGE CONSERVATION AND COMMUNICATION BY DIGITAL MODELING TOOLS. CASE STUDIES: MINOR ARCHITECTURES OF THE THIRTIES IN THE TURIN AREA
}

\author{
A. Bruno jr. ${ }^{\mathrm{a}, *}$, R. Spallone ${ }^{\mathrm{b}}$ \\ a DIST, Interuniversity Department of Regional and Urban Studies and Planning, Politecnico di Torino, Viale Mattioli 3910125 \\ Torino, Italy; SITI, Higher Institute on Territorial Systems for Innovation, Via Pier Carlo Boggio 6110138 Torino, Italy - \\ andrea.bruno@polito.it \\ ${ }^{\mathrm{b}}$ DIST, Interuniversity Department of Regional and Urban Studies and Planning, Politecnico di Torino, Viale Mattioli 3910125 \\ Torino, Italy - roberta.spallone@polito.it
}

Commission VI, WG VI/4

KEY WORDS: Digital cultural heritage, digital documentation, historical reconstruction, virtual archive, 3D modeling, animation, contemporary architecture, restoration

\begin{abstract}
:
Between the end of the twenties and the beginning of the World war two Turin, as the most of the Italian cities, was endowed by the fascist regime of many new buildings to guarantee its visibility and to control the territory: the fascist party main houses and the local ones.

The style that was adopted for these constructions was inspired by the guide lines of the Modern movement which were spreading by a generation of architects as Le Corbusier, Gropius, Mendelsohn.

At the end of the war many buildings were reconverted to several functions that led heavy transformations not respectful of the original worth, other were demolished.

Today it's possible to rebuild those lost architectures in their primal format as it was created by their architects on paper (and in their mind). This process can guarantee the three-dimensional perception, the authenticity of the materials and the placement into the Turin urban tissue, using static and dynamic digital representation systems. The "three-dimensional re-drawing" of the projects, thought as an heuristic practice devoted to reveal the original idea of the project, inserts itself in a digital model of the urban and natural context as we can live it today, to simulate the perceptive effects that the building could stir up today. The modeling skills are the basis to product videos able to explore the relationship between the environment and "re-built architectures", describing with the synthetic movie techniques, the main formal and perceptive roots. The model represents a scientific product that can be involved in a virtual archive of cultural goods to preserve the collective memory of the architectural and urban past image of Turin.
\end{abstract}

\section{INTRODUCTION}

The history of the buildings that were created in Italy during the fascist period can be divided in two antithetic moments: their origin that was celebrated as a new way to realize architecture that had to be very representative of the radical process of modernization in which the fascist party wanted to lead the country. The huge production of public buildings to endow Italy of educational, sanitary, sporting, administrative structures together with a lot of infrastructural and town planning interventions were constantly propagandized on the magazines of that time as a positive results of the Italian renewal.

The second moment offers a totally different scenario: after the war most of these once acclaimed buildings started their slow but inexorable decay, some of them were transformed without any attention to their original shape, some others were demolished, maybe paying for their belonging to one of the darkest page of Italian history. The loss of this important

\footnotetext{
* Corresponding author.

${ }^{1}$ The research project was led by Andrea Bruno jr. and Roberta Spallone. Andrea Bruno jr. is author of headings 1, 2, 3, 8; Roberta Spallone is author of headings 4, 5, 6, 7. 3D models in the figures come from the bachelor' thesis of Francesco Carota, Gabriele Businaro and Francesco Calarco, students of Architecture at Politecnico di Torino
}

heritage represents a tentative of cancelling a chapter of the history of a country that on the contrary must be read to the future generations, including negative facts but also pointing out the original solutions presented by the architects of that period. All this architecture that was changed or destroyed can be shown today again using the digital technology in a process of strict respect of the original project lines. While in the past most of the reconstructive 3D modeling was applied to archaeological sites and ancient settlements and buildings, or, even, to masterpieces of contemporary architecture and unbuilt designs of pioneering masters of modern architecture, only recently minor architecture, which constitutes a common heritage of knowledge and experience, otherwise destined to disappear from the collective memory, has drawn the attention of researchers. In this paper we will develop some consideration about the potentialities of digital modeling in the ambit of minor architecture, considered as cultural heritage, and present some case studies in the Turin area ${ }^{1}$. 


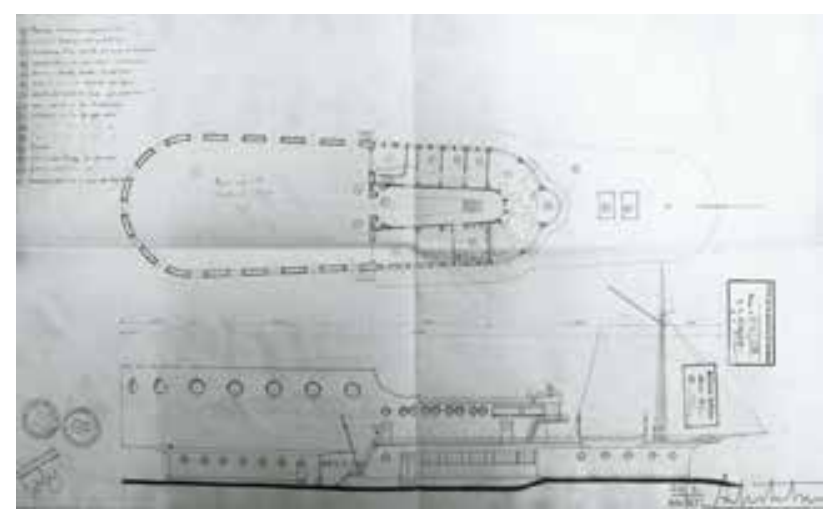

Figure 1. Archival drawing of the 'Casa del Marinaretto' by Costantino Costantini, 1936. Plan and elevation.

\section{BUILDINGS FOR THE CONTROL OF THE TERRITORY: THE ORIGINALITY OF TURIN CASE AS A REASON TO PRESERVE}

Turin counts one main fascist party house, built by Costantino Costantini in 1932, a minor one, the 'Casa rionale del Balilla di via Guastalla', always by Costantini,1934, and fifteen local houses, but only five of them were built. In addition to these we have to consider the 'Casa del Marinaretto', another Costantini work, which will be deep described in the case studies section (Montanari, 1992).

Every single building is different from the other in its formal image also if contains all the requested functions of the regulations given from the central government for this kind of buildings.

The main house is a mediation between the classical lines, using archs and symmetry and the modern materials, congruent with the thesis of the italian version of Modern movement annonuced by the Gruppo 7 in 1926, the on the contrary the minor of via Guastalla is completely devoted to the language of the european Modern movement, evoking the lesson of the german Expressionism.

Two of the other preserved minor houses (only three of the original five) show an elegant way to use the traditional material as the brick not plaster covered on a architectural body that exalt the clearness of the shape (Magnaghi, Monge, Re, 1995).

The third one, the local fascist house 'Amos Maramotti' gives the main role to a 28 meters glass tower that overhangs the entrance and represents the fascist symbol, leaving simple

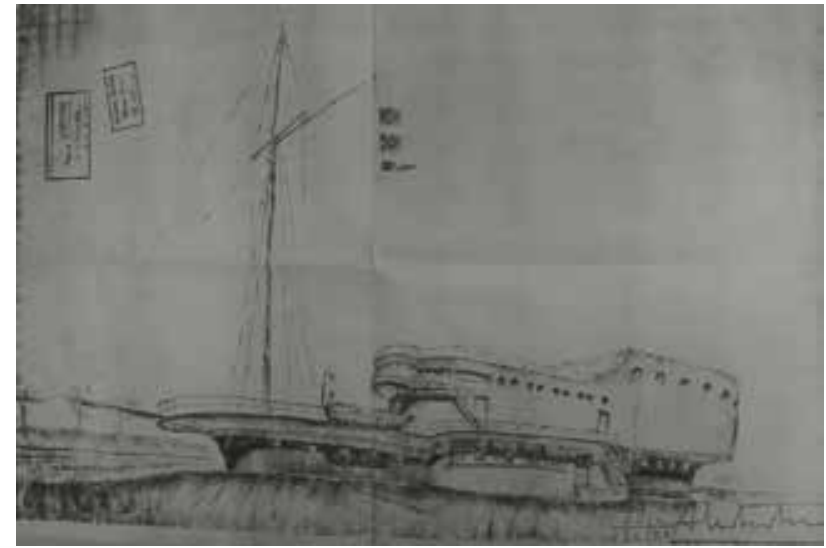

Figure 2. Archival drawing of the 'Casa del Marinaretto'. Perspective view.

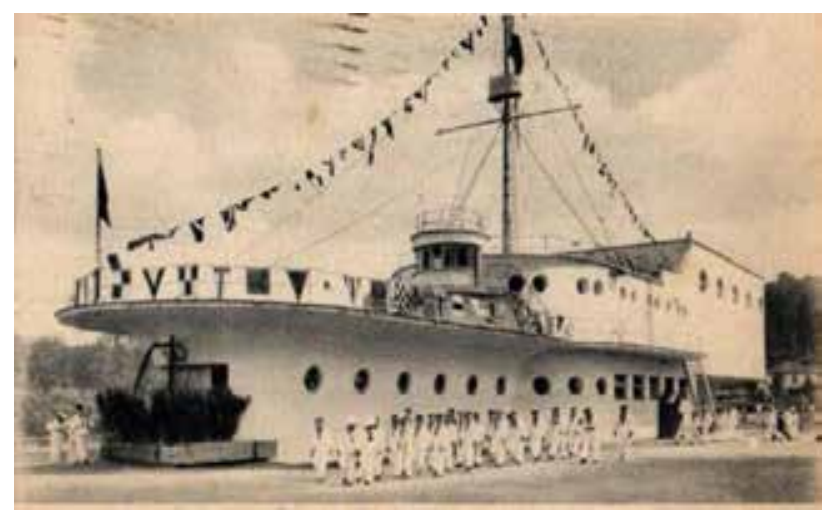

Figure 3. Vintage postcard of the 'Casa del Marinaretto' with young people wearing Navy uniform.

compositive lines to the rest of the building (Viglino, Bruno jr., Muzzarini, 2000).

The actual situation of these buildings it's discouraging: hard transformations have denied the original creation: the main house, today an universitarian site, has its windows covered of mirror glasses and the original iron shutters with a thin section substituted for heavy aluminium elements; the Guastalla house, after a wrong restoration work, is going to degrade; the two brick facades local houses are transformated and used as a police departement and a medical centre, with hard transformations and demolitions to facilitate the new destination of use; the Maramotti is more preserved but has lost the meaning of its symbol, for self evident reasons, lives today as a banal scholastic institute.

The worst sort was reserved to the 'Casa del Marinaretto', maybe the most original building, that was demolished without any consideration in the early sixties.

\section{WHY RE-BUILD A LOST ARCHITECTURE?}

The physical preservation of these architectures appears today hard to carry on, because of the lacking attention of the Italian culture to these kind of buildings and also for the economic and financial situation of this period of world crisis. The minor towns can't be able to support strategies of architectural restoration in absence of valid profit feedback, so the future of these buildings become always more difficult. The possibility to obtain economic profits from the sale of them to private enterprises that will transform in more desirable objects as

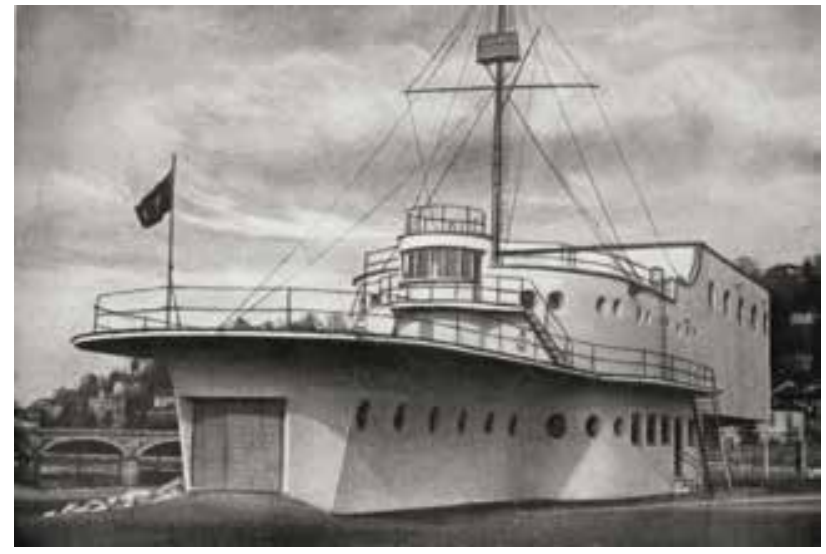

Figure 4. Historical photograph of the 'Casa del Marinaretto' 


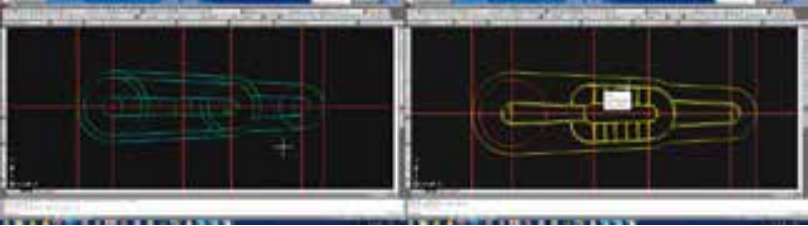

Figure 5. Graphical analysis: identification of latent geometries and plan of the 'Casa del Marinaretto'. Drawings by F. Carota.

apartments or office sites, leads the municipality far away from the adoption of regulations for the preservation of them as the ones utilized for ancient buildings. So the only way to conserve the memory of the original image of this part of the architectural history of our country is to provide to a reconstruction using the digital technologies. This process is really possible because of the existence of the original documents and drawings in the town and national archives, together with the photographic material published in the magazines and the newspapers of that time. The first step is a severe analysis of all the preserved documentation that must have the objective to reach the authenticity of the original project. The examination of the drawings can often demonstrate the difference between the architect's first idea and the physical realization. This point puts the researcher in front of a choice: operating a reconstruction that will show the building how it was when it was standing or follow the reconstruction of the building how its creator supposed it during his creative act.

The second opportunity appears more fascinating because permits the reconstruction of the building but also of the original way of thinking the architecture of the designers of another time: the choices they made about elements, materials, solutions that in the building phases were abandoned for various causes. This way of progress guarantees the absolute respect of the originality and offers an authenticity that's not only related to the imagine of the lost building but even to its conception.

The construction of a digital archive of these metaphysical architectures could constitute an important resource for the knowledge of the history of the development of the towns and because of the limited costs assure the conservation of fundamental memories that connect the line of the tale of architecture through the $\mathrm{xx}$ century. The three case studies here presented concern two examples of these particular minor fascist party houses and in addition we have included the case of a little theatre built at the end of thirties that adopts the same architectural style and that today is in a complete abandoned state: the theatre of Susa, a small town close to Turin, designed

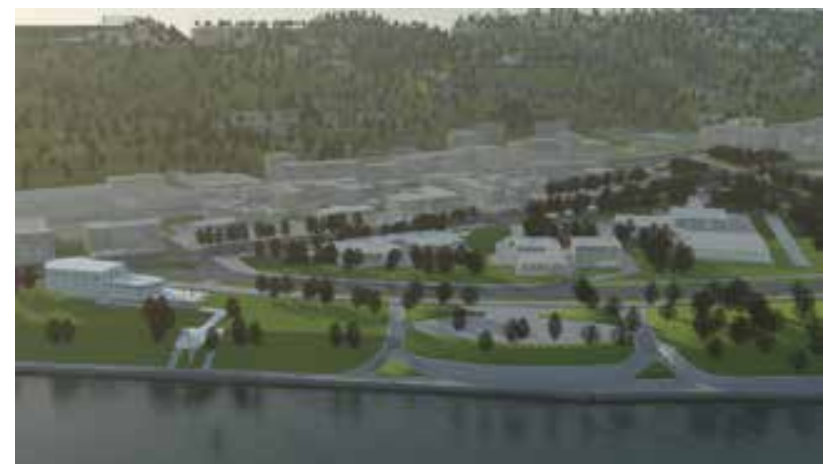

Figure 6.Conceptual rendering of the 'Casa del Marinaretto' inserted in environmental context: bird-eye view. Screen-shot from video by F. Carota.

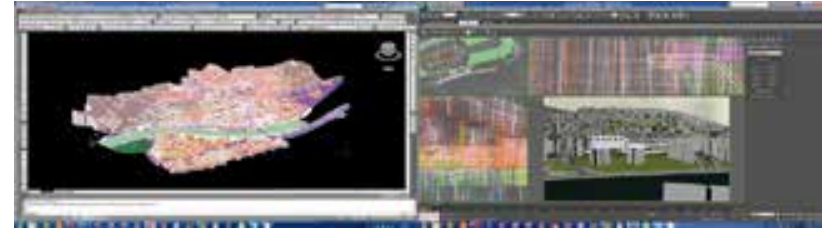

Figure 7. Modeling and rendering of urban and environmental context of 'Casa del Marinaretto'. Digital model by F. Carota.

by the genial minor architect Otto Maraini, who was architect, painter, sculptor, writer of novels and poems. He represents an effective example, among many others, of high creativity and technical capability that was erased together with his buildings just because he was working during an historical negative period (Bruno jr., 2004).

\section{DIGITAL RECONSTRUCTION OF MINOR ARCHITECTURE OF THE CONTEMPORARY: STATE OF ART}

As said before, only recently minor architecture, increasingly seen as a cultural heritage, has become the subject of reconstructive modeling.

Several reconstruction techniques are inspired by Pagnano and Docci theories and methodologies of graphical analysis, thanks to which the drawing is identified with the model of understanding (Pagnano, 2003, Docci, 2009).

Fall in this field a didactic experience carried out by Albisinni and a research work by Maggio.

Albisinni asserted the role of reconstructive drawing and modeling as critical tools both for the analysis of architectural language, and for the reinterpretation of architectural works. In particular, he underlined the possibilities offered by dynamic digital models of visualizing not only the logical construction of the interpretation, but also the sequence of operations of decomposition and typological classification (Albisinni, 2006).

In this context he promoted a didactic activity aimed to constitute a digital archive of Leonardo Savioli's works, built in Tuscany between the 40 s and 80 s.

Thanks to original drawings kept in the State Archives of Florence, the students reconstructed several 3D digital models visualized by clay rendering, orthographic views and cut-away perspectives.

Maggio conducted some researches on 'forgotten' architectures of the Thirties.

They are some buildings of the fascist period: Palazzo Rindone (1936-41) in Catania by Salvatore Caronia (Maggio, 2006), the

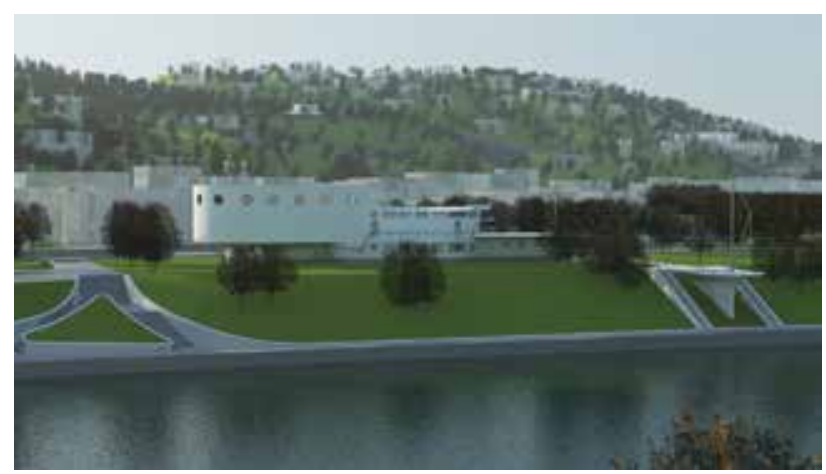

Figure 8. View from the opposite side of river of the 'Casa del Marinaretto': human-eye view. Screen-shot by F. Carota. 


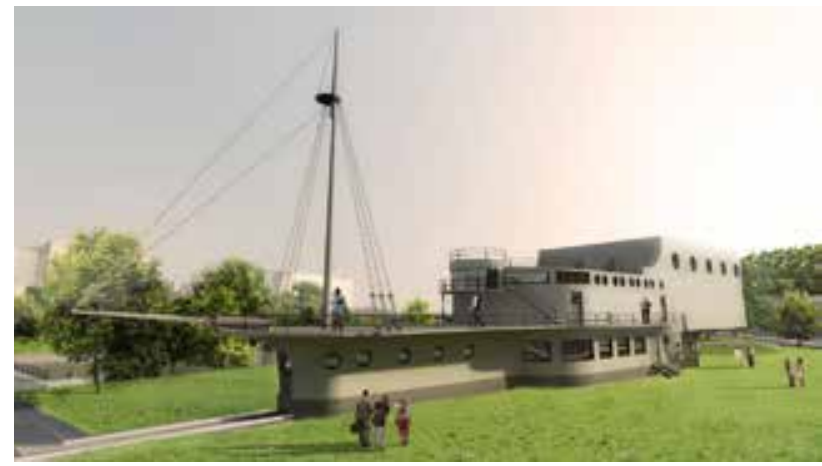

Figure 9. Photorealistic rendering of the 'Casa del Marinaretto'. Modeling and rendering by F. Carota.

Fascist House (1929) by Enrico Del Debbio, and the Post Office (1936) by Angiolo Mazzoni, both in Agrigento (Maggio, 2008). In the research on Palazzo Rindone in Catania, Maggio represented the architectural axis of the building by a sequence of perspective views of the reconstructive $3 \mathrm{D}$ model and verified in plan and section the presence of the geometric criteria stated in the Caronia's writings.

In the studies on Fascist House and Post Office, both overlooking a square of Agrigento, the author compared 3D models drawn out the archival design drawings and the survey of still existing buildings. He also underlined the relationships between the construction of these two architectures and the transformations of urban tissue.

\section{REPRESENTATION METHODS AND TECHNIQUES OF RECONSTRUCTIVE 3D MODELING}

Thanks to the most recent technological developments in the field of computer graphics, dynamic and hyper-medial visualizations have burst on the scene of architectural representation methods, traditionally static. Several digitally based techniques, such as 3D modeling, animation, montage, virtual and augmented realities are establishing as primary emerging modes of architectural representation.

This phenomenon is involving, with different aims and results, both the process of architectural design and the analysis and documentation of architectural heritage.

The representation of architectural heritage assumes the meaning of a heuristic and interpretative method, and its communication the role of a conveying of knowledge tool.

Reconstructive 3D modeling is a way to understand the object and the environment in which it was built, starting from original archive drawings, photographs, papers and, when it's possible, surveys: it becomes an important tool of historic and iconographic research, because it allows reviving a building and its context, whether it is partly, or totally, demolished, lost, or hide in the body of a building heavily altered, or, finally, is going to be irreversibly transformed.

Representation and communication concern the knowledge data, results of documentation phases. Digital models are the most useful database for collecting and synthesizing these analysis phases.

The extreme care in implementing 3D reconstructions is the final result of a new attention paid by the stakeholders to the communication capability of information technologies, both as for the large audience and the narrow scientific community. It was required to the producers of these models to adopt a language as simple as possible (De Francesco, D'Andrea, 2008), with the aim to share information and diffuse them in a readily

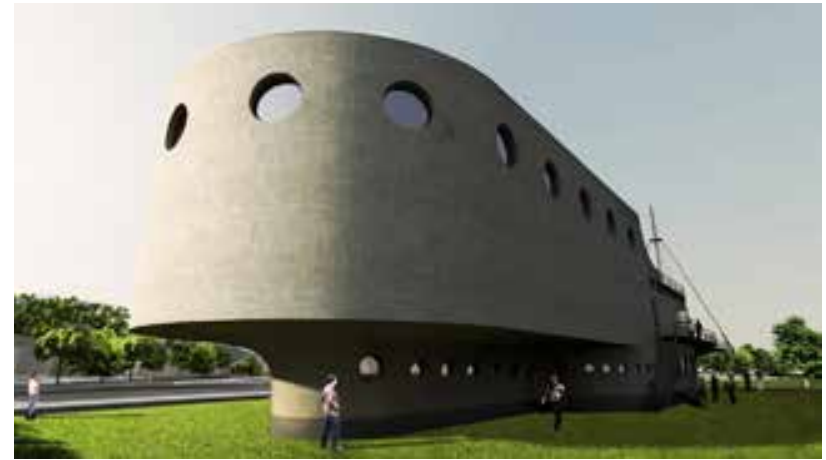

Figure 10. Photorealistic rendering of the 'Casa del Marinaretto'. Human-eye perspective view by F. Carota.

understandable form to a wide-ranging spectrum of public. Thanks to these models, the era of graphic papers that only the specialists can decipher is over.

In the present research project, we propose methodologies and techniques that can actively contribute to widen the knowledge and the understanding of the Cultural Heritage and support its sharing, in the firm conviction that safeguard and fruition should go together.

There are several stages in the 3D reconstruction of a building. These include the gathering of source information, the interpretation of this information, the comparison with contemporaneous examples, the development of 2D blueprints and 3D geometric model of the building and its context, the texture mapping, the addition of lights and, finally, the rendering.

In the reconstructive digital models the complexity of real buildings gives way to a geometric simplification which has, in any case, a high level of spatial control of the object and far exceeds the axonometric and perspective representations, (Moriconi, 2001).

That is why a central moment, in the operational strategy that ascertains the attributes -geometry, topology and photometry-, is the definition of the level of details (Gaiani, 2004). Since all the models are simplifications and schematizations of the reality, there is always a difference between the real and the level of details that are included in the model.

3D digital modeling offers, as a result, infinite possibilities of observation -which means also survey-: from the objective visualization of a cylindrical projection -orthographic or isometric- to the subjective visualization of a conical projection -perspective- (Spallone, 2007). The model thus becomes an essential tool to check the validity of reconstructive hypotheses and the congruence between the building elements.

3D computer models allow more enhanced and more controlled interaction between users and models; they are able to cover the whole range of possible models in a single system of representation (Maldonado, 2005).

The increasingly enhancements of digital technologies, also in the ambit of rendering, allow producing high-level photorealistic imagery: digital images seem photographs of the object, represented as if it had just been built. In this way, several times, photorealism become hyperrealism overcoming the limits of truth likeness. Is for this reason that we prefer 3D models visualized in conceptual style by clay renders, simulating physical maquettes. Instead of materials we prefer applying to the elements of digital models their quality of transparency and opacity. This kind of renders allows appreciate the shape generation, the geometric relationships between the object and its context, the perception of interior and exterior 


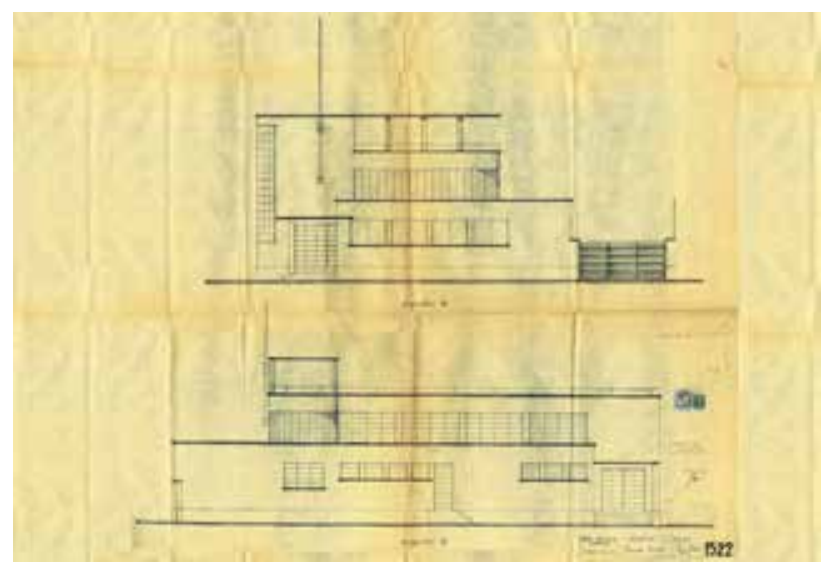

Figure 11. Archival drawing of the 'Casa rionale del Balilla di via Guastalla', by Costantino Costantini, 1933. Elevation.

spaces. When 3D model becomes part of animated sequences, only some stop-images are rendered by soft realistic imagery. In any case we share with Ogleby the idea that what is lacking presently is both an ontology for visual literacy in the area of virtual heritage, and some method of adding to the viewer's understanding through the supply of supporting information (Ogleby, 2007).

\section{FROM 3D MODELING TO VIDEO STORYTELLING}

With infographic support, digital drawing simulates a hypothetical reality, goes beyond the limitations of the static and allows interaction with any type of sign. With the creation of virtual images, infographic technology represents what is perhaps the most appropriate tool for interpreting the complexity of reality (Moriconi, 2001).

The ability to access the fourth dimension, through the construction of a sequence of images, constitutes a specific prerogative of digital representation, which goes beyond the static constraint imposed by conventional methods of representation (Garzino, Spallone, Lo Turco, 2011).

Manovich dates back the rise of the movie camera as a universal paradigm for interaction with data represented on three dimensions to the $1980 \mathrm{~s}$ and $90 \mathrm{~s}$, when interaction between users and virtual models through an interface began to use

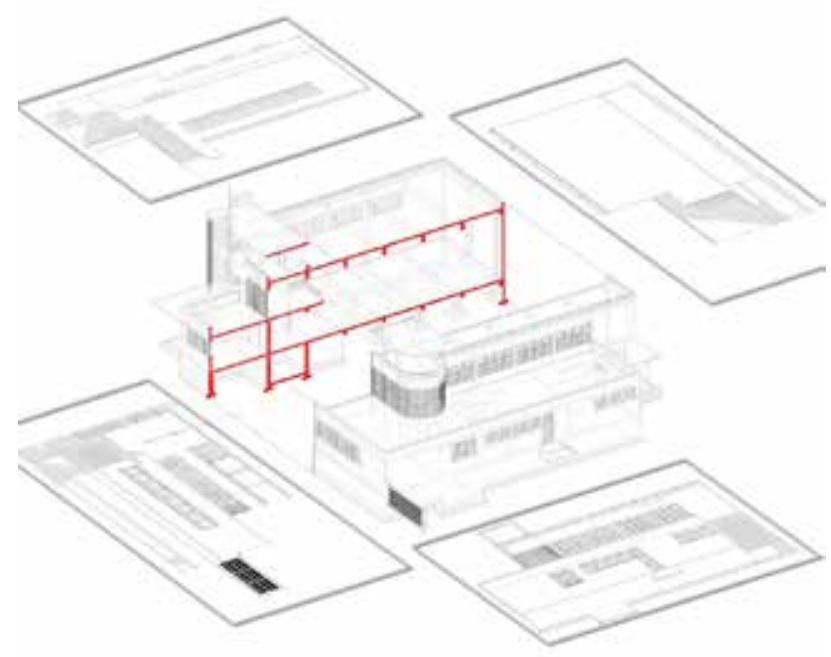

Figure 12. Blueprints for 3D modeling of the 'Casa rionale del Balilla di via Guastalla'. BIM model by G. Businaro.

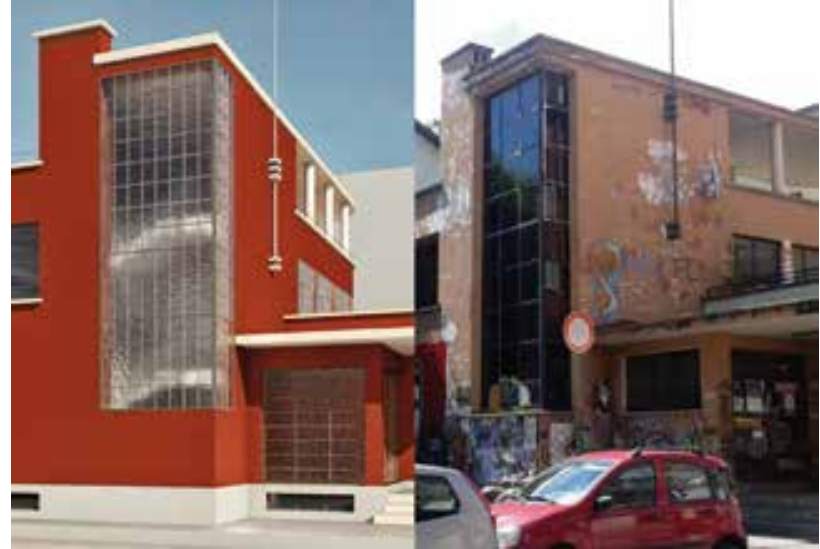

Figure 13. Comparison of digital reconstruction and current condition of the 'Casa rionale del Balilla di via Guastalla'. BIM model by G. Businaro.

actions like zooms, tilts, pans and tracks (Manovich, 2001). As a new medium, the animation of digital models requires the establishment of new relationships with disciplines such as communication sciences and cinema engineering and with technologies like that of video games and it must also pass the test of comparisons with the established conventional technologies of film production (Breen, Breen, 2008).

The production of movie and animation of $3 \mathrm{D}$ models has to focus on well organized sequences relating space, event and movement.

This triggers a critical discussion on the ontological nature of films, on their narrative form and on their character of exploring human emotions, and it implies the attention of architectural videos to the perceptual effects produced by relations between persons and space.

Three dimensional digital models frequently constitute the basis for the production of particularly effective visualizations, using a variety of techniques, for different purposes. As Engeli noted, the creation of specific messages relating to space requires an in-depth knowledge of the characteristics intrinsic to the different possibilities and to the aspects that it is wished to emphasize. An object that is viewed can be interpreted in different ways. The main parameters -light, materials, perspective- can bring out the nature of an object, work against it, reveal new information and add or hide aspects of the object (Engeli, 1999).

Paraphrasing McLuhan, the image is not the architecture, it is the message: it must stimulate the imagination of an observer to imagine life going on and activities being performed within the spaces hypothesized. That is why the images will show something more than objective and realistic representations of space. They will reveal subjective interpretations, generated and influenced by instruments selected with care.

Movies generated starting from 3D digital models, applied to the reconstruction of cultural heritage, are a powerful medium for verifying the perceptive quality of the virtual visit in space and time. The communication clearness and immediacy could be verified in this respect (Spallone, Lo Turco, Sanna, 2009).

Additionally, the introduction of the time dimension to a certain extent introduces a dynamic element in the representation and in the knowledge of its subject. While the representation that followed the 'paper path' refers to a precise moment in history, the representation that unfolds as a succession of images on the screen emerges as a becoming, a process.

The 4D representation can assume the task to document the scholars' interpretation about the shape generation, the building 


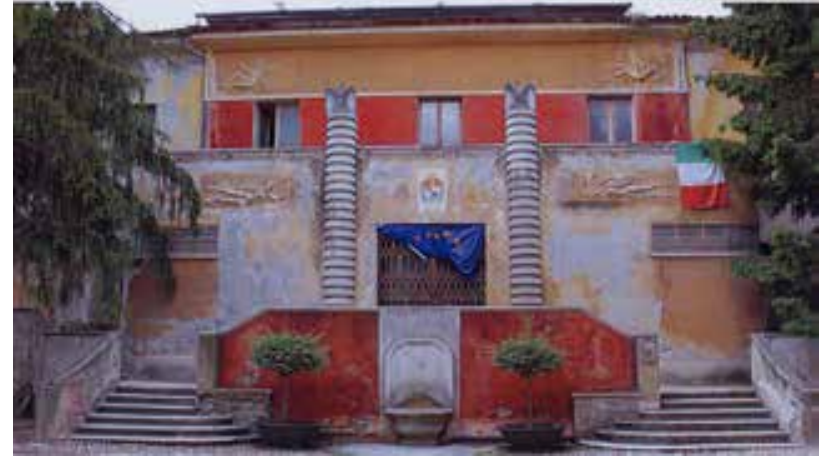

Figure 14. Current photograph of main façade of the 'Teatro civico di Susa' by Otto Maraini.

technologies and phases, and the transformation during the time. All these interpretations are founded on the heuristic analysis of sources, data and surveys.

Through the analysis of the most important data and their correlation with the historical sources it will be possible to get a very detailed idea of the work's original image, but this is still just an idea. Virtual restoration, therefore, becomes the graphic representation of a reconstructed ideal image just as it has formed through the collected data interpretation. Even a very detailed graphic reconstruction, of an architectural product, aimed at giving the viewer a stimulating image of reality, will always necessarily be the result of a synthesis. This synthesis implies the exploitation of specific aspects to the detriment of others and consequently a data loss (Galifi, P., Moretti, S., Aoyagi, M., 2002).

Looking at the technological development within interactivity, we foresee future application of real-time visualization to our reconstructive models.

Migliari explains that a interactive dynamic model provides not a single image or a certain flow of images, fixed by video makers, but it provides endless possibilities for the flow of images, static and dynamic, that are the result of choice, even arbitrary, but always subjective, of those who explores the model itself (Migliari, 2008).

Following Migliari and his method of representation, called 'interactive dynamic perspective', we will propose to apply these new techniques for exploring our 3D architectural models in the virtual space.

\section{CASE STUDIES AND DEVELOPING WORKING METHOD}

The 'Casa del Marinaretto' is one of the lost architectures, in

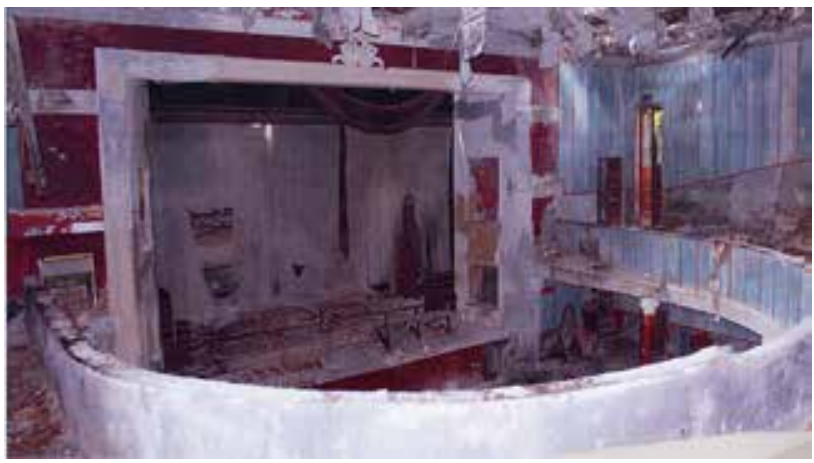

Figure 15. Current photograph of the interior of the 'Teatro civico di Susa'.

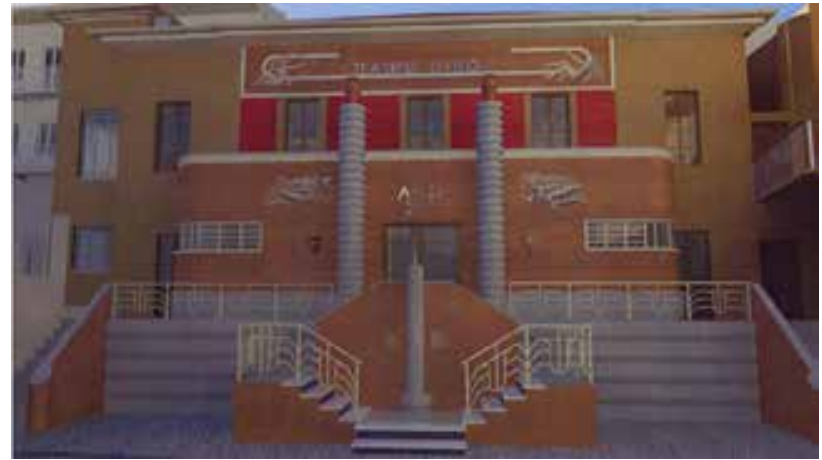

Figure 16. Digital reconstruction of the 'Teatro civico di Susa' main façade. Modeling and rendering by F. Calarco.

spite of its paradigmatic role as an Italian example of the expressionist style. It was designed by Costantino Costantini close to the river Po, looking like a big 'urban anchored ship' of huge impact, with the function of youth recreation center. In the Sixties has been demolished to permit the building of some not valued architectures, cancelling the memory of a high quality architectural product with international inspiration. This case study moves after the rigorous analysis of the original drawings preserved in the Turin archives, some old photographs and vintage postcard (Figures 1-4). The comparison between these sources reveals the difference between the original idea drawn on paper and the slightly different construction.

In this case study, we preferred the reconstruction of this building according to its original version as it was drawn by the architect for the first time, in order to re-propose his creative process. The graphical analysis applied to the building ground floor plan led to the reading of the relationship between recurring straight and curved elements - always quarters of circle or semicircle - (Figure 5).

The 3D reconstruction of Costantini's project, inserts itself into a digital model of the present urban and natural context, characterized by the presence of the hilly backdrop and river, to which the building was connected through a wharf for lowering boats.

The modeling works are the basis for the production of a video that explores the relationship between the actual image of Turin and the 'Casa del Marinaretto' and describes, with the synthetic language of the movie technique, the original shapes and the emotional reactions, the same as it was real (Figure 6-8).

The narrative, after exploring the relationship between building and environment by a fly-through and providing a functional analysis referred to different levels of 3D model, alternates animated sequences at head height, displayed in a conceptual

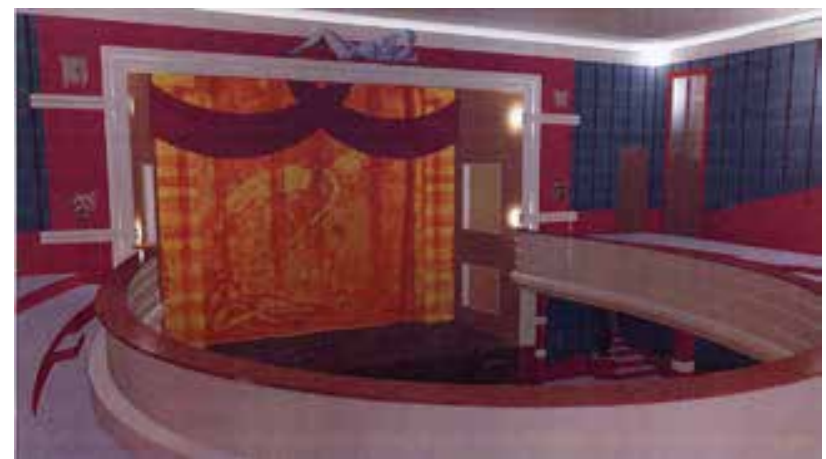

Figure 17. Digital reconstruction of the interior of the 'Teatro civico di Susa'. Modeling and rendering by F. Calarco. 
visual style, and photorealistic stop-image that develop the perceptive values of the work (Figures 9-10).

The 'Casa rionale del Balilla di via Guastalla' was built by the same Costantini with the aim of accommodate the youth organizations and at the same time to ensure a gym to an adjacent school.

This building, now in a poor state of preservation, has been object in the years of many arbitrary transformations that changed not only the shape but also the authenticity of the materials. It exemplifies the architect's ability to adopt the rationalist language, working on the sharpness of the shape, the absence of ornamentation, the use of materials and technical choices consistent with modern era, such as the use of glass bricks and roofing flat. The result is of great balance and lightness, free from rhetoric of the regime or by selfcomplacency.

The technical drawings kept in the Archivio Storico of Turin offer the real possibility of analyzing the building shape as the architect had designed (Figure 11), some others written documents allow us fragmentarily reconstructing some technical details and original materials while photographs of the time are not preserved.

The digital model of this building was realized by BIM technologies with the aim of creating a database useful for managing the predictable actions of functional requalification and energy efficiency improvements.

The functional breakdown and the identification of stylistic features related to rationalist models are flanked to the comparison of the project specifications and the current conditions of obsolescence, also highlighting the different interpretations of construction, internal changes, and variations in the color treatment of internal and external, through the juxtaposition of reconstructive photorealistic rendering and current photographs (Figures 12-13).

The project of the 'Teatro Civico di Susa' by Otto Maraini consists in the reshaping, updating of technical installations and design of furniture and decorations of the previous late nineteenth-century theatre and the restyling of the façades.

The more incisive intervention concerned the furniture and the scenery. The stylistic image of the new theater was generated through the mixture of core elements of the artistic culture of Maraini and symbols dear to the rhetoric of the fascist regime.

The building is currently in poor condition due to the state of abandonment in which lies from the 80s (Figures 14, 16).

In this case $3 \mathrm{D}$ modeling and movie are focused on internal spaces and paths to verify the perceptual effects of interiors provided by furniture, scenery and decoration, today disappeared, lightened by the original artificial lights (Figures $15,17)$.

The objects of our case studies are very different in their state of conservation (ranging from demolished buildings to those in a state of neglect), in the possibility of access and expected restoration projects, as well as in the type and consistency of documentation relating to the various architectures. This involves the use of different analysis methods and modeling strategies and techniques.

Moreover, the need of analyzing the building placing it in the urban and environmental landscape in which it lives today, or would live, generates the need to calibrate the modeling level of detail of the artifact and its context.

At the same time it is necessary a wide research on the architect, his poetics and other realizations, aimed at recognizing recurring stylistic characters and integrating eventual lost parts.

The variety of our case studies could be object of some generalizations, becoming method for the continuation of our research.
The analysis activities consist of the reconstruction, even philological, through the re-drawing of the archival drawings, possibly supplemented by other documentary sources, which can enrich the mainly geometric data arising from technical drawings, and could provide information on materials, colors, building techniques and characteristics of the surrounding environment.

When the building is still in existence, the direct survey, extended to the surroundings, provides the exact measures which can be compared with drawings' dimensions.

During the representation phases, the re-drawing of plans, elevations and sections involves the check of projective correspondences, aimed to three-dimensional synthesis, and the possible need to interpret inconsistencies and blanks. In this way the act of modeling may enhance knowledge acquisition, not only for others, but do that for the modeler as well (Vandevyvere, Neuckermans, De Jonge, 2005).

Regarding the next stages of modeling, the drawings created are the basis of the 'blue-prints' technique, in which the twodimensional drawings which write-up archive drawings in vector format, are placed on orthogonal planes in the space of the digital work, so be able to directly infer the geometric and dimensional references.

2D drawings could also be the basis of graphical analysis aimed at finding regulator patterns, harmonic proportions and modular grids that were part of the cultural background and methodology of architects during the period considered.

The 3D model level of detail, compared to the ratio between scale and contents of the original drawings, conveys the geometric simplifications (also different for the building and the context) necessary to avoid excessive modeling times, considering the distance from the object of projection's centres, static or dynamic, to be set in the visualization phase (Spallone, Bruno jr., 2013).

The built context and the terrain are modeled starting from the cities' numerical cartography and any additional information obtained through Web Map Services and direct surveys. Once created the terrain mesh and traced the streets, are modeled the green and buildings, simply extruded. Probably this laborious phase of modeling, in the future could be replaced by procedural urban modeling techniques or by including the model within the recent visualization tools of the landscape, now being implemented by Google Earth.

As said, during the render phase we prefer applying plaster material to the whole model and differentiate its colors, according to built or natural elements, and finally lighting the model with sunlight.

Photorealistic rendering, which shifts the focus from the geometric and formal aspects to the perceptual ones, are used in the video sequences only for some stop-images.

The research project foresees the construction of a geographic information system, aimed to geo-referencing each building, reconstructed using digital models included in the urban and environmental context and animated by generating video sequences and / or translating phases of construction and joined with synthetic descriptions, archival documents, photographs, other digital processing etc.

\section{CONCLUSIONS}

The construction of digital archives, which allow not only the preservation of written texts, original drawings and vintage images related to architecture of the past, takes on greater importance when these precious documents are flanked to scientifically rigorous reconstructions, based on the close relationship between the disciplines of architectural history and 
representation. The applications tested through case studies briefly described in this paper, revealed that a process of analytical knowledge, aims to highlight the historical authenticity of architectural heritage (existing or lost) through an accurate archival research and the consequent transformation of the acquired data in a series of drawings aimed, as ultimate goal, at achieving a three-dimensional representation, faithful to the project's original lines, revealing the materials chosen by the author and 'surveyable' in its entirety, is an exhaustive example of interdisciplinarity between the two architectural disciplines. The result, of course perfectible and implementable, generates a new model of conservation, which allows not only the activation of an archive reported to heritage still existing, tracing the history of their origins and transformations made in the time, but also the preservation of heritage disappeared today, although it has represented a decisive role and a historic moment for the construction of the history of a city or territory. It is also useful to remember that in economically difficult times such as the one we are experiencing, the establishment and construction of digital archives by following the methodology above described proves itself suitably feasible, allowing in a first stage, the preservation of the architectural heritage memory referring to specific periods and later providing a basis of absolute importance and scientific correctness usable in future interventions of restoration or recovery, that in the coming years will focus more and more on the architectural heritage of the twentieth century, as you can easily guess since now.

\section{REFERENCES}

Albisinni, P., 2006. Il modello digitale per l'analisi di architetture d'autore. Un'esperienza didattica dedicata a Leonardo Savioli. In: Unali, M., Edt. Lo spazio digitale dell'architettura italiana. Idee, ricerche, scuole, mappa. Kappa, Roma, pp. 169-175.

Breen, J., Breen, J., 2008. Critical Observations and Strategic Perspectives at Half-time. In: Terzidis, K., Proceedings of First international Conference on Critical Digital: What Matter(s)?, Harvard University Graduate School of Design, pp. 129-136.

Bruno jr., A., 2004. Otto Maraini. Architetto artista. Celid, Torino.

De Francesco, G., D'Andrea, A., 2008. Standards and guidelines for quality digital cultural three-dimensional content creation. In: Proceedings of 14th VSMM 2008. Digital Heritage, pp. 229-233.

Docci, M., 2009. Disegno e analisi grafica. Laterza, RomaBari.

Engeli, M., 1999. Storie digitali. Poetiche della comunicazione. Testo\&Immagine, Torino.

Gaiani, M., 2004. Del disegno e del modello: rappresentazioni per il disegno industriale / About the drawing and the model: representation for industrial design. In: Migliari, R., Edt. Disegno come modello / Drawing as Model. Edizioni Kappa, Roma, pp. 45-58 and 91-98.

Galifi, P., Moretti, S., Aoyagi, M., 2002. The Archaeological Reconstructions, Methodologies and Instruments for a Graphic Representation of an Idea. University of Tokyo, Faculty of Engineering.

Garzino, G., Spallone, R., Lo Turco, M., 2011. Strategie digitali per modelli conoscitivi / Digital strategies for knowledge based models. In: Garzino, G., Edt. Disegno (e) in_formazione. Disegno politecnico. / Drawing (and) information. Polytechnic drawing. Maggioli, Sant'Arcangelo di Romagna, pp 70-111.
Maggio, F., 2006. Analisi grafica di un'opera di Salvatore Caronia Roberti. Palazzo Rindone a Catania. Iknos, pp. 163192.

Maggio, F. 2008. Enrico Del Debbio e Angelo Mazzoni ad Agrigento. Disegnare, 37, pp. 58-71.

Maggio, F., Villa, M., 2008. Architettura demolita. Modelli abitativi alla $V$ Triennale di Milano. Ridisegno e analisi grafica. Edizioni Caracol, Palermo.

Magnaghi, A., Monge, M., Re, L., 1995. Guida all'architettura moderna di Torino. Lindau, Torino.

Maldonado, T. 2005. Reale e virtuale. Feltrinelli, Milano.

Manovich, L., 2001. The Language of New Media. MIT Press, Cambridge.

Migliari, R., 2008. Prospettiva dinamica interattiva. La tecnologia dei videogiochi per l'esplorazione di modelli 3D di architettura. Edizioni Kappa, Roma.

Montanari, G., 1992. Interventi urbani e architetture pubbliche negli anni Trenta. Il caso del Piemonte. CLUT, Torino, 1992.

Moriconi, C., 2001. Il modello virtuale. In: Soletti, A., Belardi, P., Cataliotti, F. Claudio Moriconi professione infografico. Università degli Studi di Perugia, pp. 20-30.

Ogleby, C., 2007. The 'Truthlikeness' of Virtual Reality Reconstructions of Architectural Heritage: Concepts and Metadata. In: Proceedings of 2nd International Workshop 3DARCH'2007. 3D Virtual Reconstruction and Visualization of Complex Architectures, International Archives of Photogrammetry, Remote Sensing and Spatial Information Sciences, Vol. XXXVI-5/W47, F. Remondino, S. El-Hakim Edt..

Pagnano, G., 2003. Presentazione. In: Ikhnos. Analisi grafica e storia della rappresentazione, Siracusa, pp. 7-10.

Spallone, R., 2007. 3D digital modelling as a method for the reconstruction of the historical image of the city: the case of piazza Bodoni in Turin (Italy) at the end of nineteenth century. In: Proceedings of 21 st International CIPA Symposium. Anticipating the Future of the Cultural Past, Athens.

Spallone, R., Lo Turco, M., Sanna, M., 2009. Fourth dimension for representing and communicating architectural heritage. In: Proceedings of 22nd International CIPA Symposium. Digital Documentation, Interpretation \& Presentation of Cultural Heritage, Kyoto, pp. 201-206.

Spallone, R., Bruno jr., A., 2013. Patrimoni e memoria. Ricostruzioni digitali di architetture minori degli anni Trenta in area torinese / Heritage and memory. Digital reconstructions of minor architectures of the Thirties in Turin area. In: Proceedings of XXXV Convegno Internazionale dei Docenti della Rappresentazione Patrimoni e siti Unesco. Memoria, misura e armonia / Heritage and Unesco sites. Memory, measure and Harmony, Matera. Gangemi, Roma, pp. 909-916.

Vandevyvere, H., Neuckermans, H., De Jonge, K., 2005. Digital historical reconstruction: case studies of an interdisciplinary task. In: Proceedings of EuropIA.10, Augmented Heritage, Damascus 13-15 September 2005.

Viglino, M., Bruno jr., A., Muzzarini, D., 2000. Oltre il portone. Intorno al centro. Torino bella, Torino. 